\title{
EAPCI Position Statement on Invasive Management of Acute Coronary Syndromes during the COVID-19 pandemic
}

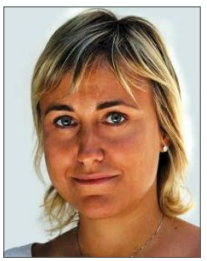

\author{
Alaide Chieffo ${ }^{1}$, Giulio G. Stefanini², Susanna Price ${ }^{3}$, Emanuele Barbato ${ }^{4}$, Giuseppe Tarantini ${ }^{5}$, \\ Nicole Karam ${ }^{6}$, Raul Moreno ${ }^{7}$, Gill Louise Buchanan ${ }^{8}$, Martine Gilard9 ${ }^{9}$, Sigrun Halvorsen ${ }^{10}$, \\ Kurt Huber ${ }^{11}$, Stefan James ${ }^{12}$, Franz-Josef Neumann ${ }^{13}$, Helge Möllmann ${ }^{14}$, Marco Roffi ${ }^{15}$, \\ Guido Tavazzi ${ }^{16}$, Josepa Mauri Ferré ${ }^{17}$, Stephan Windecker ${ }^{18}$, Dariusz Dudek ${ }^{19 \bullet}$, \\ Andreas Baumbach ${ }^{20 *}$
}

1. Interventional Cardiology Unit, IRCCS San Raffaele Hospital, Milan, Italy; 2. Humanitas Clinical and Research Hospital IRCCS, Rozzano, Milan, Italy; 3. Royal Brompton Hospital, London, UK; 4. Department of Advanced Biomedical Sciences University Federico II, Naples, Italy; 5. Interventional Cardiology Unit, Department of Cardiac, Thoracic, Vascular Sciences and Public Health, University of Padova, Padua, Italy; 6. European Hospital Georges Pompidou (Cardiology Department) and University of Paris, Paris, France; 7. Cardiology Department, Hospital La Paz and IDIPAZ, Madrid, Spain; 8. Department of Cardiology, North Cumbria Integrated Care NHS Foundation Trust, Cumbria, UK; 9. Service de Cardiologie, Brest University Hospital, Brest, France; 10. Department of Cardiology, Oslo University Hospital Ulleval, and University of Oslo, Oslo, Norway; 11. 3rd Department of Medicine, Cardiology and Intensive Care Medicine, Wilhelminen Hospital, and Sigmund Freud University, Medical School, Vienna, Austria; 12. Department of Medical Sciences, Cardiology and Uppsala Clinical Research Center, Uppsala University, Sweden; 13. Division of Cardiology and Angiology II University Heart Centre Freiburg, Bad Krozingen, Germany; 14. Department of Cardiology St.-Johannes-Hospital Klinik für Innere Medizin I, Dortmund, Germany; 15. Division of Cardiology, University Hospitals, Geneva, Switzerland; 16. Department of clinical-surgical, diagnostic and pediatric sciences, Unit of anaesthesia and intensive care, Fondazione Policlinico San Matteo Hospital IRCCS, Pavia, Italy; 17. Hospital Universitari Germans Trias i Pujol, Badalona, Spain; 18. Department of Cardiology, Swiss Cardiovascular Center, University Hospital Bern, Bern, Switzerland; 19. Institute of Cardiology, Jagiellonian University Medical College, Krakow, Poland and Maria Cecilia Hospital GVM, Cotignola, Ravenna, Italy; 20. Centre for Cardiovascular Medicine and Devices, William Harvey Research Institute, Queen Mary University of London, Barts Heart Centre, London, UK and Yale University School of Medicine, New Haven, CT, USA

- These authors are to be considered as last authors.

This paper also includes supplementary data published online at: https://eurointervention.pcronline.com/doi/10.4244/EIJY20M05_01

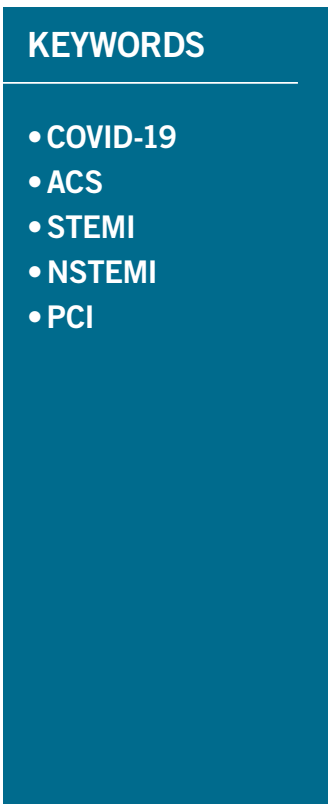

\section{Abstract}

The coronavirus disease 2019 (COVID-19) pandemic poses an unprecedented challenge to healthcare worldwide. The infection can be life threatening and require intensive care treatment. The transmission of the disease poses a risk to both patients and healthcare workers. The number of patients requiring hospital admission and intensive care may overwhelm health systems and negatively affect standard care for patients presenting with conditions needing emergency interventions. This position statements aims to assist cardiologists in the invasive management of acute coronary syndrome (ACS) patients in the context of the COVID-19 pandemic. To that end, we assembled a panel of interventional cardiologists and acute cardiac care specialists appointed by the European Association of Percutaneous Cardiovascular Interventions (EAPCI) and from the Acute Cardiovascular Care Association (ACVC) and included the experience from the first and worst affected areas in Europe. Modified diagnostic and treatment algorithms are proposed to adapt evidence-based protocols for this unprecedented challenge. Various clinical scenarios, as well as management algorithms for patients with a diagnosed or suspected COVID-19 infection, presenting with ST- and non-ST-segment elevation ACS are described. In addition, we address the need for re-organization of ACS networks, with redistribution of hub and spoke hospitals, as well as for in-hospital reorganization of emergency rooms and cardiac units, with examples coming from multiple European countries. Furthermore, we provide a guidance to reorganization of catheterization laboratories and, importantly, measures for protection of healthcare providers involved with invasive procedures.

\footnotetext{
*Corresponding author: Centre for Cardiovascular Medicine and Devices, William Harvey Research Institute, Queen Mary University of London, Charterhouse Square, London, EC1M 6BQ, UK. Tel: +44 2036758740.E-mail: a.baumbach@qmul.ac.uk 


\section{Abbreviations}

ACS acute coronary syndrome

ED emergency department

HCWs healthcare workers

NSTEMI non-ST-elevation myocardial infarction

PCI percutaneous coronary intervention

PPE personal protective equipment

STEMI ST-elevation myocardial infarction

\section{Introduction}

The coronavirus disease 2019 (COVID-19) pandemic is a major burden on healthcare systems and is imposing a change in practice in multiple disciplines, including interventional cardiology. The crisis is showing a particular impact on the diagnostic and treatment pathways for patients presenting with acute coronary syndromes (ACS).

Challenges for the networks include the strain on the hospital infrastructures, bed and catheterization laboratories (cathlabs) capacity, and transportation due to the number of severely ill COVID-19 patients admitted to hospitals. The potential COVID-19 infection status of each new patient has to be considered to reduce the spread of the infection. The severe acute respiratory syndrome coronavirus-2 (SARS-CoV-2) has the same stability in aerosols and on surfaces as SARSCoV-1, but the rate of transmission is higher. ${ }^{1}$ Its environmental stability may contribute to the transmission of the virus in hospitals. It is therefore fundamental to guarantee proper protection of healthcare workers (HCWs) for their own health, to minimize the risk of spreading the infection to other HCWs and patients, and finally to guarantee the proper level of care in cathlabs in the case of suspected or confirmed COVID-19 patients.

Difficult decisions have to be made, taking into account the different stages of the pandemic in each country, region, and individual hospital. The European Association of Percutaneous Cardiovascular Interventions (EAPCI) have assembled a panel of interventional cardiologists with first-hand experience from affected areas in Europe and expertise in network organization, with support from authors from the Acute Cardiovascular Care Association (ACVC), experienced in the treatment of severely ill patients with acute COVID-19 infection.

The objective of this position statement is to provide guidance regarding optimal invasive management of patients with ACS during the COVID-19 pandemic whilst minimizing the risk of infection for both patients and HCWs. This document reviews the clinical scenarios in different phases of the crisis, reviews diagnostic difficulties specific to ACS presentations with raised troponins, proposes modified algorithms for invasive management, re-organization of ACS networks, hospitals, and cathlabs, and provides a guidance to maintain $\mathrm{HCW}$ safety during invasive procedures.

This statement is created as non-binding advice and does not interfere with any official local or national guidance in place. The advice given is valid only during the time of the COVID-19 pandemic, as declared by the World Health Organization.

\section{Categorization of invasive procedures according to their impact on regional/national healthcare services}

The rearrangement of the healthcare service required to face the COVID-19 pandemic has posed a series of relevant issues regarding prioritization of cardiac invasive procedures. ${ }^{2,3}$

Regions in Europe differ substantially in terms of local healthcare resources, pandemic density of the COVID-19 outbreak, changes of the pandemic over time, and therefore access to healthcare services other than COVID-19 care. These variations have a wide range of implications for national/regional healthcare services, national healthcare authorities, and in-hospital redistribution of resources. Regions (also within the same country) may be categorized into three groups according to the degree of involvement in the pandemic, with subsequent different implications for the healthcare system, as summarized in Table 1.

The indications provided in this document refer mainly to the scenario of heavy involvement and, in part, to the scenario of moderate involvement. Importantly, healthcare services should continue to be provided according to standard of care as described by current clinical practice guidelines, ${ }^{4}$ as long as the degree of regional involvement in the pandemic allows it. The rationale to importantly reduce the number of elective hospitalizations is three-fold: (i) to increase capacity for COVID-19 patients; (ii) to reduce the unjustified exposure of individuals (i.e. patients in need of non-urgent procedures and their relatives) to the hospital and surrounding environment; and (iii) to reduce the exposure of HCWs to asymptomatic COVID-19 patients.

This strategy comes at the expense of time-to-treatment delays for urgent cardiovascular interventions and extension of waiting times for patients in need of elective coronary, heart valve, or other cardiovascular procedures.

In this context, a strategy is needed to identify patients who are in a stable condition, therefore allowing a postponement of procedures, and those who are not. An obvious concern is to maintain the standard of care and timely access of patients with ACS, including acute myocardial infarction (AMI), to reperfusion

Table 1 Regional involvement in the epidemic and impact on the healthcare system

\begin{tabular}{|l|l|l|l|}
\hline \multirow{2}{*}{} & \multicolumn{3}{|c|}{ Regional involvement in the epidemic } \\
\cline { 2 - 4 } & \multicolumn{1}{|c|}{ Marginal } & \multicolumn{1}{c|}{ Moderate } & \multicolumn{1}{c|}{ Heavy } \\
\hline $\begin{array}{l}\text { Impact on the healthcare } \\
\text { system }\end{array}$ & $\begin{array}{l}\text { None or minor restrictions in provision } \\
\text { of regular healthcare services }\end{array}$ & $\begin{array}{l}\text { Major restrictions in provision of } \\
\text { regular healthcare services }\end{array}$ & $\begin{array}{l}\text { Inability to provide regular } \\
\text { healthcare services }\end{array}$ \\
\hline
\end{tabular}


therapy. In patients with chronic coronary syndromes (CCSs), principles of prioritization can be based on risk stratification, taking into account the prognostic implications of symptoms and the presence of known critical disease of the left main stem or of the proximal left anterior descending coronary artery at prior coronary angiography or at coronary computed tomography angiography (CCTA). ${ }^{4}$ Table 2 summarizes a categorization of invasive cardiac procedures according to urgency that may be implemented in areas affected by the COVID-19 pandemic.

\section{Myocardial injury: the role of cardiac biomarkers}

Acute myocardial injury is defined as a rise and fall in cardiac troponin (cTn) with at least one value above the $99^{\text {th }}$ percentile upper reference limit (URL), attributable to cardiovascular or non-cardiovascular causes. ${ }^{5}$ Implementation of high sensitivity (hs)- cTn assays, along with the application of the $4^{\text {th }}$ Universal definition of myocardial infarction (MI), has led to an increased accuracy in the differentiation between type $1 \mathrm{MI}$, type $2 \mathrm{MI}$, and acute and chronic myocardial injury. ${ }^{6}$ However, no cut-off values for cTn can reliably differentiate between acute myocardial injury and different types of MI. Whilst myocardial injury and type 2 MI are associated with a worse long-term prognosis than type $1 \mathrm{MI},{ }^{7}$ there is no consensus regarding how to manage these patients, except for treatment of the underlying disease.

In recent reports on patients hospitalized with COVID-19, $5-25 \%$ had elevations in cTn, with a higher prevalence in those admitted to the intensive care unit (ICU) and also in those who died. ${ }^{8,9}$ Troponin elevation increased with COVID-19 illness deterioration and was associated with a worse prognosis. ${ }^{10}$ Interestingly, serum concentrations remained in the normal range in most survivors. ${ }^{10,11}$ Brain natriuretic peptide (BNP)/N-terminal proBNP (NT-proBNP) levels are also reported to be elevated in
COVID-19 patients, particularly in those with a concurrent troponin elevation. ${ }^{10,11}$ The concentrations of BNP/NT-proBNP in a patient with COVID-19 should be seen as the combination of the presence/extent of pre-existing cardiac disease and/or the acute haemodynamic stress related to COVID-19 infection. The mechanisms underlying acute myocardial injury in COVID-19 patients are poorly understood, and may include direct viral and cytopathic effects, cytokine release syndrome potentially leading to microinfarction, ${ }^{12}$ type I MI (in patients with or without previous coronary artery disease), type $2 \mathrm{MI}$ in patients with severe respiratory distress/severe hypoxaemia, myocarditis, ${ }^{13}$ shock as part of COVID-19, or Takotsubo syndrome. ${ }^{14}$ The role of right ventricular involvement in biomarker elevation remains to be determined. In patients with COVID-19 infection, the classical cardiac symptoms suggesting cardiac ischaemia may be misleading or absent, in particular in those intubated and ventilated. A rise and/or fall of hs-cTn alone may be insufficient to diagnose AMI, and ECG as well as echocardiographic parameters have to be integrated to target the most appropriate management strategy. ${ }^{15,16}$

The use of coronary angiography for COVID-19-positive patients with elevation in cTn should be restricted to those in whom type $1 \mathrm{MI}$ is suspected.

Troponin elevations in patients with COVID-19 infection seem to be lower than in most cases of ACS or acute myocarditis. In the case of marked elevation (e.g. $>5$ times the ULN) in a patient who is not critically ill, myocarditis, Takotsubo syndrome, spontaneous coronary dissection, or type 1 MI should be suspected.

\section{KEY MESSAGES}

- Myocardial injury, as quantified by cardiac troponin T/I concentrations, may occur in COVID-19 infections as in other pneumonias. The level of cardiac troponins correlates with disease severity and also seems to have a prognostic value.

Table 2. Strategical categorization of coronary interventions during COVID-19 pandemic.

\begin{tabular}{|c|c|c|c|c|}
\hline $\begin{array}{l}\text { Clinical } \\
\text { condition }\end{array}$ & $\begin{array}{c}\text { EMERGENT } \\
\text { (do not postpone) }\end{array}$ & $\begin{array}{c}\text { URGENT } \\
\text { (perform within days)* }\end{array}$ & $\begin{array}{c}\text { LOWER PRIORITY } \\
\text { (perform within }<3 \text { months)* }\end{array}$ & $\begin{array}{l}\text { ELECTIVE } \\
\text { (may be postponed } \\
>3 \text { months) }\end{array}$ \\
\hline $\begin{array}{l}\text { Ischaemic heart } \\
\text { disease }\end{array}$ & $\begin{array}{l}\text { - STEMI } \\
\text { - NSTE-ACS in very high } \\
\text { risk and high risk } \\
\text { patients } \\
\text { - Cardiogenic shock }\end{array}$ & $\begin{array}{l}\text { - NSTE-ACS in intermediate } \\
\text { risk patients } \\
\text { - Unstable angina } \\
\text { - Left main PCI } \\
\text { - Last remaining vessel PCI } \\
\text { - Decompensated ischaemic } \\
\text { heart failure } \\
\text { - Angina pectoris class IV } \\
\text { - CABG in patients with } \\
\text { NSTE-ACS unsuitable for PCI }\end{array}$ & $\begin{array}{l}\text { - Advanced CAD with angina } \\
\text { class III or NYHA III symptoms } \\
\text { - Staged PCI of non-IRA in } \\
\text { STEMI in patients with } \\
\text { haemodynamic stability and } \\
\text { without }>90 \% \text { lesions in } \\
\text { proximal segments of major } \\
\text { epicardial coronary arteries } \\
\text { - Proximal LAD PCI }\end{array}$ & $\begin{array}{l}\text { - CTO interventions } \\
\text { - CCS with angina } \\
\text { class II or NYHA II } \\
\text { symptoms }\end{array}$ \\
\hline $\begin{array}{l}\text { Acute/chronic } \\
\text { heart failure }\end{array}$ & $\begin{array}{l}\text { - Mechanical circulatory } \\
\text { support for cardiogenic } \\
\text { shock (<65 years) }\end{array}$ & - Urgent heart transplant & - LVAD & \\
\hline \multicolumn{5}{|c|}{$\begin{array}{l}\text { *Timing might be affected by overwhelming demand on resources in the setting of a COVID-19 pandemic. CABG, coronary artery by-pass grafting; } \\
\text { CCS, chronic coronary syndromes; CTO, chronic total occlusion; IRA, infarct related artery; LAD, left anterior descending; LVAD, left ventricle assist } \\
\text { device; LVEF, left ventricular ejection fraction; NSTE-ACS, non-ST-segment elevation acute coronary syndrome; NYHA, New York Heart Association; } \\
\text { PCI, percutaneous coronary intervention; STEMI, ST-segment elevation myocardial infarction }\end{array}$} \\
\hline
\end{tabular}


- Mild elevations in cardiac troponin T/I (e.g. <2-3 times the ULN), particularly in an older patient with pre-existing cardiac disease, do not require work-up for type $1 \mathrm{MI}$, unless strongly suggestive clinically by angina chest pain and/or ECG changes. Such mild elevations are in general well explained by preexisting cardiac disease and/or the acute injury/stress related to COVID-19 infection.

- Marked elevations in cardiac troponin T/I concentrations (e.g. $>5$ times the ULN) may indicate the presence of severe respiratory failure, tachycardia, systemic hypoxaemia, shock as part of COVID-19, myocarditis, Takotsubo syndrome, or type $1 \mathrm{MI}$ triggered by COVID-19. If no symptoms or ECG changes are suggestive of type $1 \mathrm{MI}$, echocardiography should be considered in order to help diagnose the underlying cause.

\section{Clinical scenarios}

Both ST-segment elevation myocardial infarction (STEMI) and non-ST-segment elevation myocardial infarction (NSTEMI) can occur in patients with a confirmed/suspected diagnosis or without signs or symptoms of COVID-19. In order to select the appropriate management strategy, it is important to take into consideration the clinical status of the patient and the likelihood of concomitant COVID-19. Whenever SARS-CoV-2 testing can be obtained before an invasive procedure, this strategy should be prioritized. However, in some cases, clinical presentation may require immediate intervention. In this case, or when COVID-19 is confirmed, every effort should be made to reduce the risk of viral spreading with protective measures ${ }^{17-19}$ that have to be implemented from the first contact with the patient in the emergency department (ED) or in the out-of-hospital setting

i. It is critical to differentiate patients with type $1 \mathrm{MI}$ from COVID-19 patients, who might present with troponin elevation and/or ST changes, that are associated with respiratory symptoms and chest pain, without a coronary aetiology. ${ }^{3,12}$

ii. STEMI patients can be haemodynamically stable or present with cardiogenic shock (CS) or a mechanical complication. In the latter scenarios, the need for advanced care should be assessed in the light of local resources and the patient's age and comorbidities. Appropriate treatment should not be delayed, even if COVID-19 is confirmed or suspected. Possible causes of delay in time to reperfusion are due to reluctance by the patients to call emergency numbers, the late arrival of the ambulance to pick up the patient, and then delayed time of arrival of the ambulance to the hospital due to congestion and multiple calls because of the pandemic. Nevertheless, because of need for protection of other patients and HCWs, this may lead to further in-hospital delays. ${ }^{20,21}$

iii. Actions, such as public campaigns to raise awareness, dedicated lines with an emergency number, dedicated ambulances for cardiovascular emergencies, and entry points in ED with dedicated hospital pathways (see Section 9), can be considered at appropriate stages of the pandemic aiming at reducing these delays. The initial experience in affected areas suggests that as the infection spreads, there is a period characterized by low numbers of STEMI followed by a phase of increased numbers of late presenters and related mechanical complications. ${ }^{20}$

iv. The majority of NSTEMI patients do not have ongoing ischaemia and respond well to medical treatment, allowing time to test the patients for COVID-19 infection. Very high risk NSTEMI patients should be managed according to STEMI pathways.

v. Patients with out-of-hospital cardiac arrest constitute a group of patients in which prognostic assessment is of paramount importance in order to avoid futile intubation and ICU stay at a time of limited resources. The threshold to bring out-ofhospital cardiac arrest patients to ICU and to the cathlab (in the case of STEMI or very high risk NSTEMI) depends on the capability of the hospital to admit the patient and also the clinical status of the patient upon arrival.

vi. As discussed in a recent document from the European Association of CardioVascular Imaging, chest CT is frequently used to confirm COVID-19 pneumonia and might provide possible synergies of and opportunities for cardiac imaging. ${ }^{16}$

vii. It can be considered to integrate the protocol alongside CCTA in order to exclude or confirm an ACS in COVID-19 pneumonia where elevated troponins are common.

viii. Medication of NSTEMI patients should follow the usual practice. In patients undergoing specific COVID-19 treatments, some interactions have been reported between lopinavir/ritonavir, antiviral drugs, and cardiovascular drugs. Lopinavir/ritonavir may inhibit 63 CYP3A4 with the need for dosage changes or avoidance of clopidogrel and ticagrelor and direct oral anticoagulants such as apixaban and rivaroxaban. Lopinavir/ritonavir also influence statin metabolism; therefore, atorvastatin and rosuvastatin should be administered at the lowest possible dose. ${ }^{3}$

In terms of protection, two scenarios are relevant: direct patient contact with or without the risk for aerosol generation. Invasive procedures carrying a direct risk of aerosol generation are resuscitation, intubation, transoesophageal echocardiography (this should be limited and alternatives should be taken into account such as serial transthoracic echocardiography, CT, or cardiac magnetic resonance), ${ }^{16}$ and any procedures during which the patient can become unwell, with active coughing or vomiting.

\section{STEMI: primary $\mathrm{PCI}$ vs. thrombolysis}

The COVID-19 pandemic should not compromise timely reperfusion of STEMI patients. ${ }^{20-22}$

In line with current guidelines, reperfusion therapy remains indicated in patients with symptoms of ischaemia of $<12 \mathrm{~h}$ duration and persistent ST-segment elevation in at least two contiguous ECG leads. ${ }^{22}$ Concurrently, the safety of HCWs should be ensured. ${ }^{2}$ To that end, and in the absence of previous SARS-CoV-2 testing, all STEMI patients should be managed as if they are COVID-19 
positive. We provide general guidance to address the healthcare system organization and delineate possible pathways for specific STEMI settings. The proposed actions are not evidence based, may need to be adapted to meet local hospital and health authority regulations, and may be subject to change in view of the evolving COVID-19 pandemic as described in Tables 1 and 2.

While general measures for healthcare systems on redistribution of hub and spoke hospital networks for cardiovascular emergency ${ }^{2}$ and reorganization of ER and hospital pathways are described in Sections 8 and 9, respectively, the main principles of STEMI management in the COVID-19 pandemic are the following.

i. The maximum delay from STEMI diagnosis to reperfusion of 120 min should remain the goal for reperfusion therapy under the following considerations:

a. primary percutaneous coronary intervention (PCI) remains the reperfusion therapy of choice if feasible within this time frame and performed in facilities approved for the treatment of COVID-19 patients in a safe manner for healthcare providers and other patients;

b. primary PCI pathways may be delayed during the pandemic due to delays in the delivery of care (as described in Section 4) and the implementation of protective measures (up to $60 \mathrm{~min}$ - according to multiple experiences);

c. if the target time cannot be met and fibrinolysis is not contraindicated, this should then become first-line therapy. Of note, fibrinolysis should be taken into consideration only if type $1 \mathrm{MI}$ is highly likely.

ii. As SARS-CoV-2 test results are not immediately available, any STEMI patient should be considered potentially COVID-19 positive.

iii. All STEMI patients should undergo testing for SARS-CoV-2 as soon as possible following first medical contact irrespective of reperfusion strategy, at the latest upon admission to the ICU post primary PCI. Until the result of the test is known, all precautionary measures should be taken to avoid potential infection of other patients and HCWs.

iv. All physicians involved in the management of patients with STEMI should be familiar with indications, contraindications, and dosage of fibrinolysis, and adhere to established administration protocols (Supplementary material online, Tables S1 and S2).

v. Consider immediate complete revascularization if indicated and appropriate (as reported in Table 2) in order to avoid staged procedures. This strategy would aim to reduce the need for readmissions during the ongoing crisis, limit the risk of exposure of patients and HCWs, as well as minimize hospital stay.

vi. Perform a left ventricular angiogram in patients having an invasive revascularization procedure in order to evaluate left ventricular function. Echocardiography can then be avoided in these patients, with the exception of those that become haemodynamically unstable or develop potential postSTEMI complications. ${ }^{16}$ vii. In the case of mechanical post-STEMI complications, management should follow current ESC guidelines, taking into account clinical status, accepting the need for triage in times of restricted access.

viii. Specific pathways for management of STEMI patients are illustrated in Figure 1.

\section{KEY MESSAGES}

- All STEMI patients should be managed as COVID-19 positive

- Primary PCI is first-line therapy if it can be performed in a timely fashion - 120 min from symptom onset

- Fibrinolysis if not contraindicated can be considered when the delay is longer

- Complete revascularization to be considered if indicated and appropriate

- Left ventricular angiogram instead of echo to evaluate left ventricular function

\section{NSTE-ACS: immediate, early, and conservative management}

The management of patients with non-ST-segment elevation ACS (NSTE-ACS) should be guided by risk stratification. ${ }^{23}$ As a general rule, all patients with NSTE-ACS should undergo testing for SARSCOV-2 as soon as possible following first medical contact, irrespective of treatment strategy, in order to allow HCWs to implement adequate protective measures and management pathways (Section 10).

Risk stratification should be based on the criteria as provided by ESC guidelines on NSTE-ACS. However, the pathways for these patient groups will be modified according to pressures on the network and consideration of infection control. Patients should be categorized into four risk groups (i.e. very high risk, high risk, intermediate risk, and low risk) and managed accordingly (Figure 2). At variance with ESC recommendations, we do not envisage including GRACE risk scoring during the pandemic when COVID-19 status has to be taken into account. Also, patients with a rise in troponin and no acute clinical signs of instability (ECG changes, recurrence of pain) might be managed with a primarily conservative approach. The purpose of this reclassification, which remains valid only during the time of the COVID-19 pandemic, is to unload the healthcare systems and to avoid as much as possible the risk of patient as well as $\mathrm{HCW}$ contamination in regions with intermediate and high involvement as defined in Section 2.

\section{PATIENTS AT VERY HIGH RISK}

These patients should be managed as patients with STEMI (see dedicated Section 5).

\section{PATIENTS AT HIGH RISK}

For these patients, a medical strategy aimed at stabilization and prompt execution of a SARS-CoV-2 test is recommended, whilst planning an early $(<24 \mathrm{~h})$ invasive strategy. The time of the invasive strategy may, however, be longer than $24 \mathrm{~h}$ according to the 


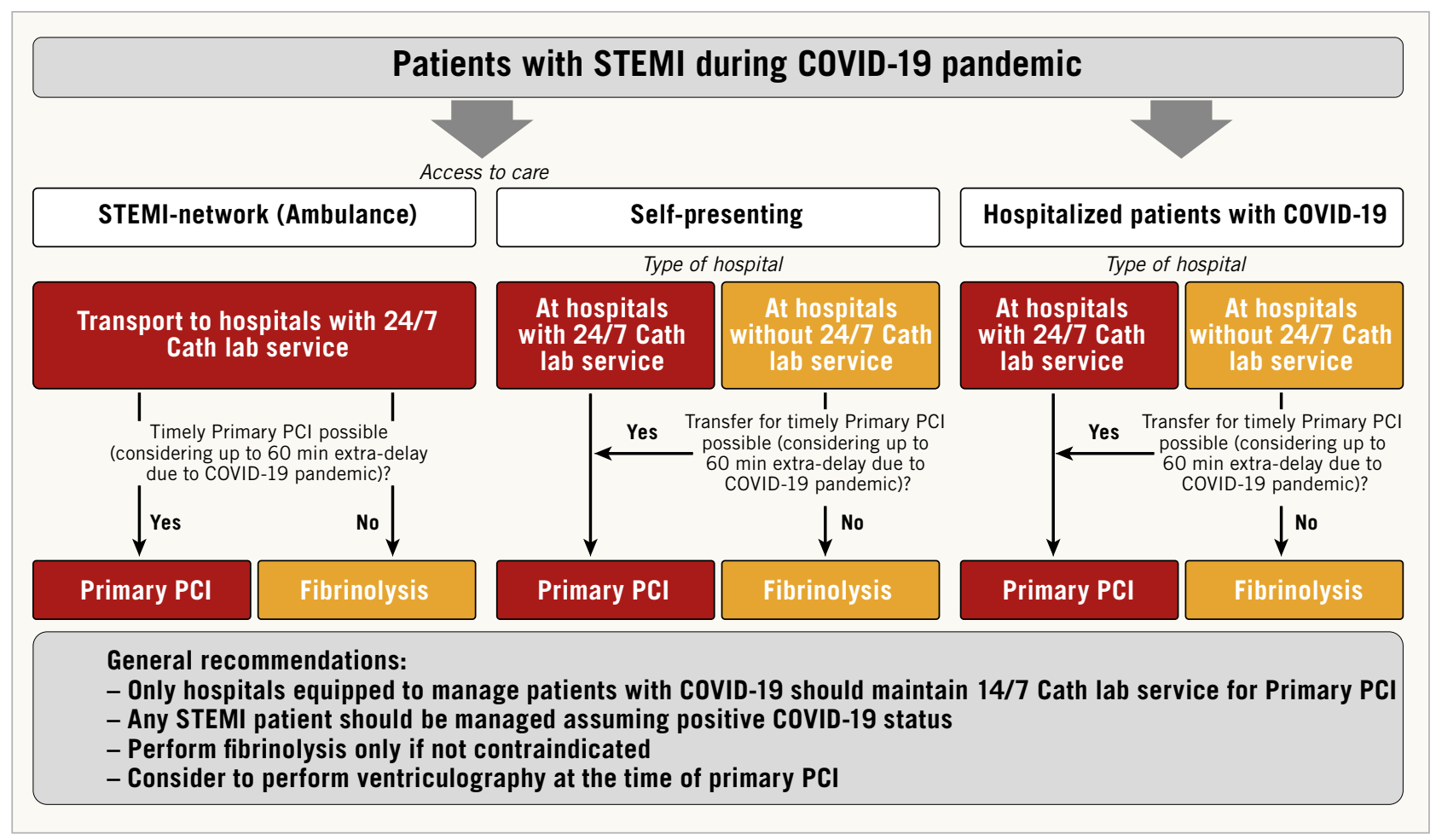

Figure 1. Management of patients with STEMI during the COVID-19 pandemic. The figure considers the following potential scenarios: (i) STEMI patients accessing care through the STEMI network (i.e. by ambulance) should be directly transported to COVID-19 hospitals with 24/7 catheterization laboratory facilities (cathlabs). If at the time of hospital arrival the dedicated COVID-19 cathlab room is not available, fibrinolysis should be considered. (ii) STEMI patients self-presenting at the emergency department of hospitals with cathlabs should undergo reperfusion in COVID-19 hospitals with 24/7 primary percutaneous coronary intervention (PCI) facilities. Otherwise, patients should be transferred. If a timely primary PCI cannot be achieved taking into account an estimated 60 min extra delay due to the COVID-19 outbreak, fibrinolysis should be considered. (iii) Patients with STEMI self-presenting at the emergency department of hospitals without cathlabs should be transferred to COVID-19 hospitals with 24/7 primary PCI facilities. If a timely primary PCI cannot be achieved taking account of the extra delay due to the COVID-19 outbreak, fibrinolysis should be considered. (iv) Hospitalized COVID patients suffering from STEMI should be treated with primary PCI if the COVID-19 hospital has 24/7 cathlab facilities. Otherwise, transfer the patient to a COVID-19 hospital with 24/7 cathlab facilities. If a timely primary PCI cannot be achieved, patients should be treated with fibrinolysis. Timely primary PCI as described in the text is a primary PCI performed within 120 min from symptom onset. It is suggested to perform left ventriculography during catheterization.

timing of testing results. In the case of a positive SARS-CoV-2 test, patients should be transferred for invasive management to a COVID-19 hospital.

\section{PATIENTS AT INTERMEDIATE RISK}

For these patients, a medical strategy aimed at stabilization and prompt execution of the SARS-CoV-2 test is recommended.

Patients should be carefully evaluated taking into consideration alternative diagnoses to type $1 \mathrm{MI}$, as described in Section 4. In the event that any of the differential diagnoses seem plausible, a noninvasive strategy should be considered and CCTA should be favoured, if equipment and expertise are available.

When there is a positive SARS-CoV-2 test, patients should be transferred for invasive management to a COVID-19 hospital. At times of high demand on the infrastructure and reduced availability of cathlabs or operators, non-invasive conservative management might be considered with early discharge from the hospital and planned clinical follow-up.

\section{PATIENTS AT LOW RISK}

A conservative strategy based on non-invasive testing is recommended for patients at low risk. A SARS-CoV-2 test is also recommended in these patients.

In NSTE-ACS patients with positive troponin and clinical signs of heart failure, echocardiography may be of importance to justify a faster invasive revascularization procedure. ${ }^{16}$

\section{KEY MESSAGES}

- Very high risk NSTE-ACS should be managed similarly to STEMI

- High risk NSTE-ACS should be tested before coronary angiography 


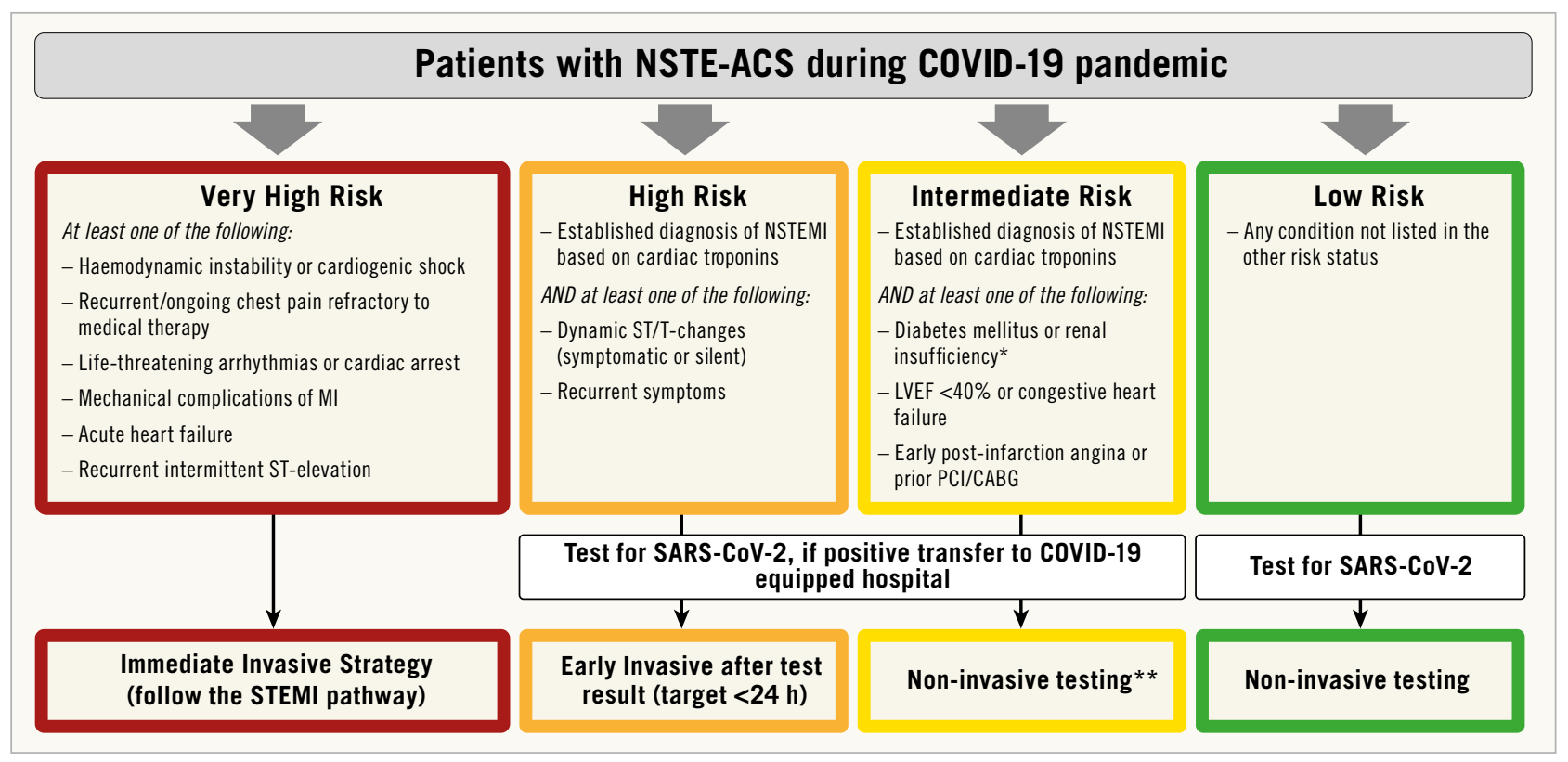

Figure 2. Recommendations for management of patients with NSTE-ACS in the context of ther COVID-19 outbreak. LVEF: left ventricular ejection fraction; MI: myocardial infarction; NSTEMI: non-ST-segment elevation MI; *estimated glomerular filtration rate

$<60 \mathrm{~mL} / \mathrm{min} / 1.73 \mathrm{~m}^{2} . *{ }^{*}$ Coronary computed tomography angiography (CCTA) should be favoured, if equipment and expertise are available. In low risk patients, other non-invasive testing might be favoured in order to shorten hospital stay. It is suggested to perform left ventriculography during catheterization.

- Intermediate risk NSTE-ACS could be evaluated non-invasively, if feasible with CCTA

- Consider adding CCTA protocol to thorax CT scan performed in COVID 19 patients

\section{Cardiogenic shock and need for mechanical cardiac support}

Cardiogenic shock (CS) is defined as a primary cardiac disorder that results in both clinical and biochemical evidence of tissue hypoperfusion. ${ }^{24}$ The severity of haemodynamic compromise ranges from being at risk of CS (stage A) to cardio-circulatory collapse, potentially requiring rescue mechanical circulatory support (MCS) (stage E). ${ }^{25}$ Importantly, recent data in such patients demonstrate shock of undetermined aetiology in up to $12 \%$ of COVID-19 patients. $^{26}$

Severe cardiac dysfunction in COVID-19-positive patients may occur from a number of mechanisms, including myocardial virus localization $^{13}$ or acute myocardial injury/type 2 MI triggered by imbalance of oxygen demand and supply associated with increased breathing work and severe hypoxaemia. ${ }^{27}$

Close monitoring of circulatory parameters and cardiac biomarkers is essential in daily ICU practice, as is the use of heart and lung ultrasound for clinical evaluation. However, to reduce exposure to infection risk for HCWs, comprehensive echocardiography may be reserved for those patients with high suspicion of cardiac involvement such as increased hs-cTn, ECG signs representing ischaemia, or haemodynamic instability. ${ }^{28,29}$
Except for viral myocarditis, ${ }^{30}$ there is limited knowledge regarding the use of percutaneous ventricular assist devices (pVADs) for haemodynamic support in previous influenza outbreaks, as more focus has been placed on respiratory support. ${ }^{31}$ However, if haemodynamic instability persists despite maximal medical therapy, the escalation to a pVAD has to be considered and patients should be transferred and further managed in expert centres which may offer different choices of MCS. 24,32

\section{INTRA-AORTIC BALLOON PUMP (IABP)}

Despite recent guideline recommendations concerning IABP use in $\mathrm{CS},{ }^{20}$ this method is still widely available in ICUs and may find its application ${ }^{24}$ in STEMI patients with a potentially increased rate of related mechanical complications during the COVID-19 pandemic.

\section{PERCUTANEOUS VENO-VENOUS (VV) OR VENO-ARTERIAL (VA) EXTRACORPOREAL MEMBRANE OXYGENATION (ECMO)}

Patients with COVID-19 present a high prevalence of developing severe acute respiratory stress syndrome (ARDS) requiring high positive end-expiratory pressure (PEEP) and driving pressure, ${ }^{33,34}$ thus leading to increased right ventricular afterload and, finally, right ventricular failure. ${ }^{35}$ In the case of refractory hypoxaemia $(\mathrm{P} / \mathrm{F}<80) /$ respiratory acidosis $\left(\mathrm{pH}<7.25\right.$ with $\mathrm{PaCO}_{2} \geq 60 \mathrm{~mm} \mathrm{Hg}$ ) despite optimal medical and ventilator strategy [titration of plateau $\left(<27 \mathrm{cmH}_{2} \mathrm{O}\right)$ and driving pressures $\left(<17 \mathrm{cmH}_{2} \mathrm{O}\right)$, pulmonary vasodilators, and pronation], VV ECMO should be considered ${ }^{36}$ also 
to down-titrate intrathoracic pressure and reduce right ventricular afterload. ${ }^{37}$ If further haemodynamic support is needed, consideration should be given to either a percutaneous oxy-right ventricular assist device (RVAD) or alternatively upgrading to VA ECMO. ${ }^{37}$

VA ECMO supports both lung and cardiac functions, and is considered the device of choice in COVID-19 patients with haemodynamic and respiratory failure. In addition, an IABP or Impella may be used to manage left ventricular over distension in patients receiving VA ECMO. ${ }^{33}$

ECMO-assisted cardiopulmonary resuscitation (ECPR) can be considered in carefully selected patients who develop cardiac arrest, considering the likelihood of poor outcomes also due to the considerable risk of infection.

Patient and device selection are vital, in particular in the COVID-19 pandemic situation where resources are limited. The aim is to support especially those patients with an acute but potentially reversible cause, such as myocarditis, pulmonary embolism, and tachycardia-related or toxicity-related cardiomyopathy before the onset of multiorgan failure. ${ }^{38,39}$

\section{KEY MESSAGES}

- Clinical outcome in CS is even worse in COVID-19 patients (30-40\% vs. $45-50 \%$ survival)

- STEMI patients in CS should be transferred and further managed in expert centres which may offer different choices of MCS

- IABP may be an option in haemodynamically depressed COVID-19 patients presenting with STEMI and mechanical complications if other MCS not available

- Veno-arterial (VA) ECMO support is considered the device of choice in COVID-19 patients with haemodynamic and respiratory failure

- Impella (or IABP) may be used to manage left ventricular overdistension in patients receiving VA ECMO.

\section{Redistribution of the hub and spoke hospital network for cardiovascular emergencies}

Time-dependent emergency healthcare networks are experiencing major disruptions after the COVID-19 outbreak, especially in those European regions most affected by the pandemic. Regions may be categorized into three groups according to the degree of involvement in the pandemic, with subsequent different implications for the healthcare system as summarized in Tables $\mathbf{1}$ and 2.

As the pandemic progresses, routine diagnostic and elective interventions are being drastically reduced and services are focusing on high-risk patients requiring urgent treatment, as described in Section 2. In some European countries, healthcare systems have identified specific COVID-19 hospitals or wards (Supplementary material online, Table S3), in an attempt to concentrate and isolate confirmed COVID-19 patients and to prevent the spread of the virus over multiple hospitals. ${ }^{2}$ COVID-19 hospitals are usually tertiary hospitals, normally serving as STEMI hubs,with an ICU and 24/7 cathlab activity. To free up these hubs, non-infected patients are sometimes transferred to non-COVID-19 hospitals after acute treatment. Human or logistic resources may be shared amongst institutions, especially when a hub is temporarily put into quarantine.

With the widespread pandemic, attempts to strictly separate COVID-19 and non-COVID-19 patients into separate management pathways and environments might become more challenging. In addition, identification of suspected COVID-19 patients is elusive, as it relies mostly on clinical symptoms or epidemiological assumptions. In fact, $50-75 \%$ of subjects positive to COVID-19 may be asymptomatic, while the remainder may develop symptoms within the reported range of $0-24$ days ${ }^{40,41}$ after contact with the virus. Therefore, all patients entering timedependent networks should be considered potentially COVID-19 positive, unless ruled out with appropriate testing, and HCWs should adopt all appropriate protective measures as described in Section 10. All these patients should be tested as soon as possible, but in the meantime should enter protected, dedicated, isolated paths and environments warranting the best available treatment (e.g. primary PCI, ICU monitoring, etc.) until infection is ruled out. Confirmed COVID-19 patients need to be transferred to dedicated COVID-19 wards or an ICU. Strategies should be guided by the availability of transport systems, cathlab facilities, teams, and infection control considerations of the local network.

\section{KEY MESSAGES}

- In regions with moderate and heavy involvement in the pandemic, the STEMI network has to be reorganized

- ACS should be directed to COVID-19 hospitals with 24/7 cathlab facilities

- Strategies should be guided by the availability of transport systems, cathlab facilities, teams, and infection control considerations of the local network.

\section{Reorganization of emergency department and hospital paths}

This section contains examples for the reorganization of ED and hospital pathways in regions with moderate or heavy involvement (Figure 3).

The ED might be divided into areas for receiving patients that are 'hot' or suspected COVID-19 and 'cold' for patients with other emergencies. It would be ideal to have a dedicated entry point and triage for cardiovascular emergencies. ${ }^{2}$ These areas should be distinct, with separate teams providing care in each of these areas to prevent the risk of cross-contamination. It should be clear regarding the entry point for each of these areas with rapid triage upon arrival to ensure the patient is in the correct place. In the setting of a suspected STEMI, the hospital should ensure a dedicated entrance to allow immediate treatment with prompt reperfusion.

Following assessment, if the patient has tested positive for COVID-19, or the infection remains a possibility, the patient 


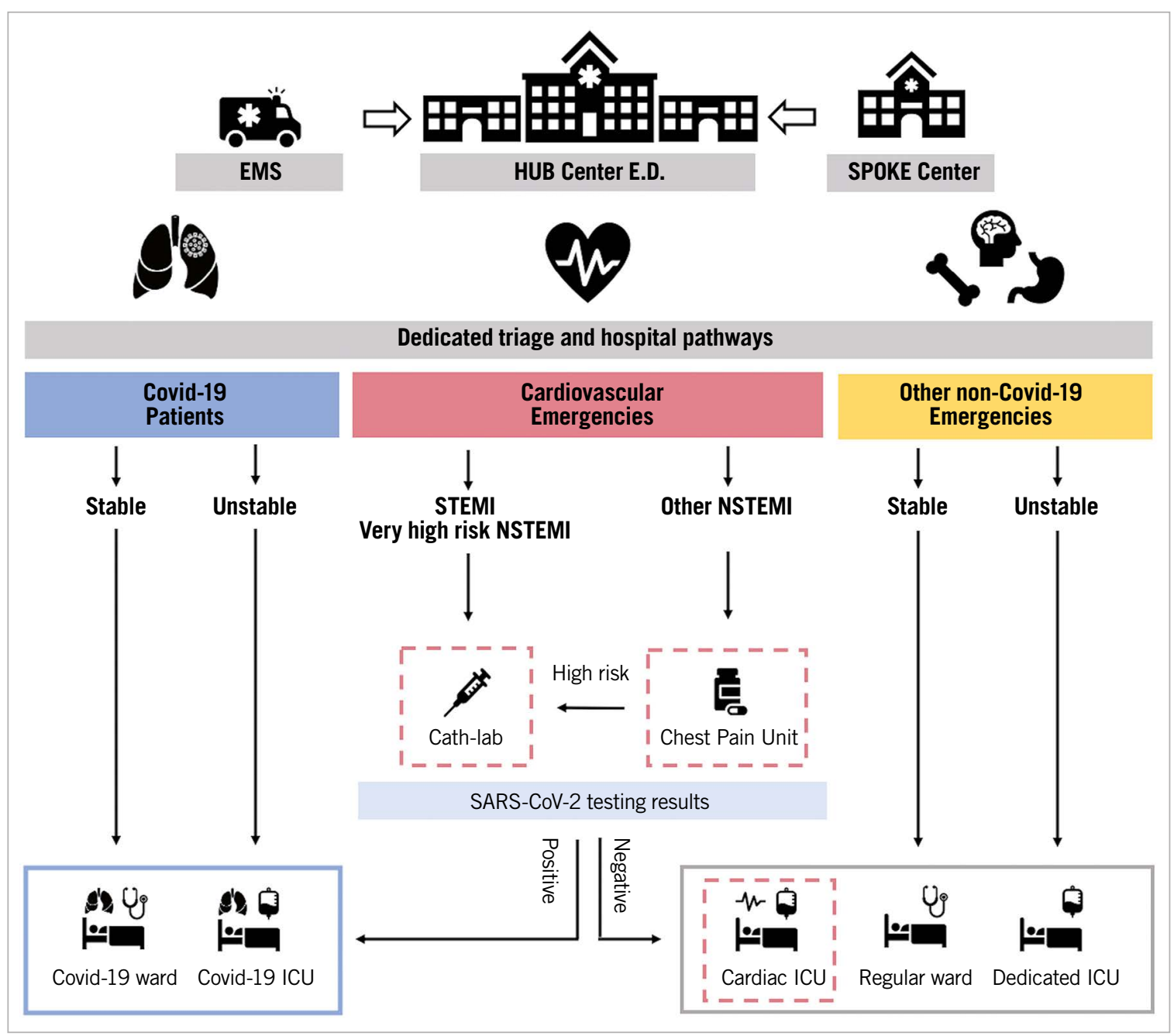

Figure 3. Reorganization of emergency department and hospital paths during COVID-19 pandemic in hub centres for an STEMI/NSTEMI network. In a hub centre for an STEMI/NSTEMI network in the emergency department, dedicated different entry points and triage as well as hospital pathways and wards are advocated for patients with diagnosed or suspected of having COVID-19 because of symptoms (blue), cardiovascular emergencies without diagnosed or suspected COVID-19 (red), and other emergencies without diagnosed or suspected COVID-19 (yellow). All patients admitted to the cardiovascular emergency triage for ACS should receive SARS-CoV-2 testing. Patients with STEMI or very high risk NSTEMI should be immediately referred to the cathlab, while those in the other NSTEMI risk categories should be referred to a dedicated chest pain unit before SARS-CoV-2 testing results are available. Patients should be further managed according to SARS-CoV-2 testing. The red dotted lines highlight the dedicated units for the management of ACS patients.

should be transferred to a specific area, where care can be provided by staff appropriately trained and with the relevant personal protective equipment (PPE) as described in Section 10. It is recommended to follow full infection control measures when transferring patients for the protection of the staff and all other patients within the hospital. As patients may be acutely unwell, critical care areas again should be divided to prevent cross-contamination. Those patients who do not require critical care might be cohorted in clearly demarcated 'hot' areas, ensuring that these areas are not in close proximity to at-risk patients, such as those who may be immunocompromised.

There should also remain some critical care 'cold' areas for those patients who may require invasive therapies, including those with unstable cardiovascular disease. Maintaining separate areas throughout the hospital for both COVID-19-positive and -negative patients will help to minimize additional infection and the related hospital mortality.

\section{KEY MESSAGES}

- The ED should be reorganized in order to have different entry points for cardiovascular emergencies and hot (COVID-19) and cold (non-COVID) areas

- Hospital pathways should be redesigned in order to allocate patients according to their admission symptoms and SARSCOV-2 test result in COVID-19 and non-COVID wards and ICU according to their clinical presentation and stability 


\section{How to prepare cath labs and guarantee protection to healthcare providers: general indications for staff and room management}

It is recommended to separate HCWs into groups to potentially reduce exposure and therefore limit the operators who may be required to be in quarantine at the same time. It is suggested to identify one dedicated cathlab for the treatment of suspected or confirmed COVID-19 cases. ${ }^{17-19,42-46}$ The dedicated cathlab has to be fully equipped with all interventional materials stored inside (catheters, guidewires, angioplasty balloons, stents, etc.), ideally behind closed cupboard doors, avoiding entry and exit of the staff members during the procedure. A daily checklist for the presence of adequate PPE in the cathlab and for a dedicated crash cart (Figure 4; Supplementary material, Table S4) should be completed. ${ }^{47,48}$

\section{DONNING AND DOFFING PROCEDURES}

All HCWs have to be routinely trained in the correct and appropriate use of PPE. Donning/doffing (the process of putting on and removing PPE) manoeuvres should be supervised by a trained observer who reads the correct sequence of PPE use to minimize the risk of contamination (Table 3).

\section{WHAT TO DO BEFORE PATIENT ARRIVAL TO THE LAB (SUSPECTED OR CONFIRMED COVID-19 PATIENT)}

i. Notify the area receiving the patient of any necessary additional precautions over and above those for the treatment of the COVID-19 patient.

ii. Maximize coordination to avoid steadying in waiting areas.

iii. Ensure during movement of the COVID-19 patient there is appropriate space around the patient to reduce the risk of cross-contamination of other patients/HCWs.

iv. Pre-alert the anaesthesiologist to consider elective intubation, If appropriate, this should be performed before arrival of the patient in the cathlab

v. Only the personnel involved directly in the cathlab should remain in the room. Identify an appropriately trained supervisor for donning/ doffing for all team members prior to arrival of the patient.

vi. Patients can wear a surgical mask during transfer and entry to the cathlab (when breathing spontaneously).

\section{WHAT TO DO DURING INTERVENTIONAL PROCEDURE IN A SUSPECTED OR CONFIRMED COVID-19 PATIENT}

i. Keep the door closed with signage to prevent entry.

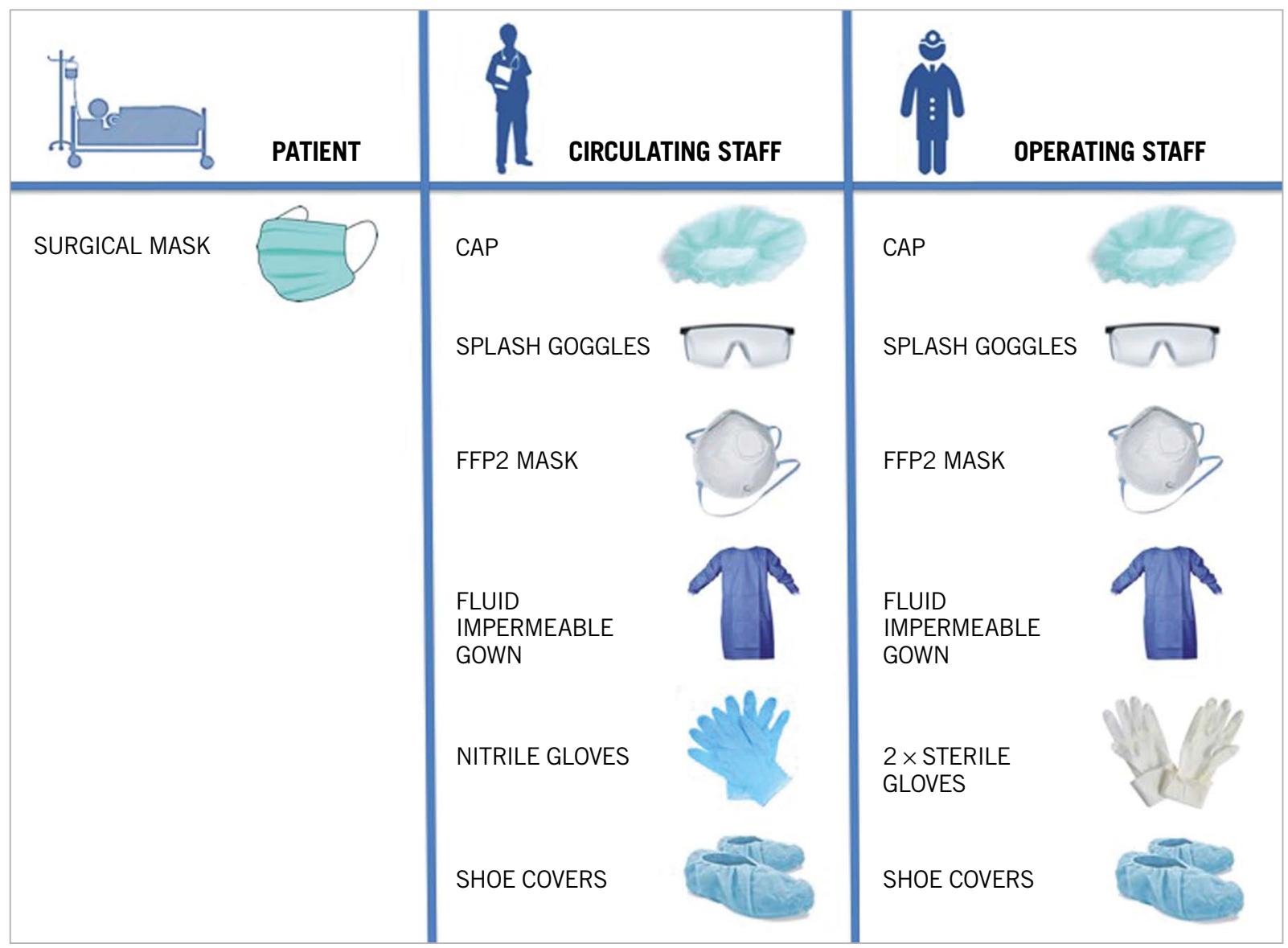

Figure 4. Individual protection equipment for cardiac health workers of cardiac invasive facilities in suspected or diagnosed COVID-19 patients. 
Table 3 Sequence of donning and doffing of PPE

Donning PPE sequence

1. Remove any personal items

2. Put on the lead apron

3. Put on a first disposable gown

4. Gather the necessary PPE and check for their integrity

5. Perform hand hygiene with soap and/or hand gel/rub

6. Put on the proper disposable respirator N95 or FFP2 standard (FFP3 available for anaesthesiologist and nurse helping on airways manoeuvres)

7. Put on hair cover

8. Put on shoe covers

9. Put on googles and/or face shield avoiding any interference with the respirator.

10. Perform hand hygiene

11. Put on the first pair of gloves

12. Put on a gown (sterile or not according to your role in the cathlab) not using the inside tie

13. Put on a second pair of gloves (over cuff), sterile if needed. Doffing PPE sequence

Inside the cathlab (or in the filter zone if available):

1. Wait until patient is out of the room; close the door.

2. Perform hand hygiene over the gloves

3. Peel off gown and gloves together and roll inside, slowly and carefully, avoiding aerosol generation

4. If gloves are removed separately, touch only the external part (use glove-in-glove or beak technique)

5. Perform hand hygiene (over the internal gloves)

6. Remove face shield and/or googles avoiding contact with face and eyes and dispose of them safely or put in a separate container for reprocessing

7. Perform hand hygiene (over the internal gloves)

8. Remove hair cover and dispose of it safely

9. Remove shoe covers and dispose of them safely

10. Perform hand hygiene (over the internal gloves)

11. Remove internal gloves and dispose of them safely

12. Perform hand hygiene

13. Step out of the cathlab and immediately close the door.

Outside the cathlab:

14. Put on another pair of gloves

15. Remove facial respirator without touching the front side of the respirator

16. Remove the gloves

17. Remove lead apron

18. Perform hand hygiene with soap and water and alcohol gel/rub.

ii. Avoid entry and exit from the room of the cathlab personnel (dedicated COVID-19 cabinet recommended).

iii. Minimize contact with the surfaces - change external gloves (or add another pair of gloves) before any new contact (e.g. before opening a tray).

iv. Keep the procedure as simple as possible, whilst maintaining good clinical care for the best outcome and in order to minimize hospital stay and readmission rates.

\section{WHAT TO DO AFTER THE COVID-19 PATIENT LEAVES THE} CATHLAB

i. Keep the door closed.

ii. Supervised doffing. If no filter zone is available, doffing could be done inside the lab, when the patient has been transferred away. The facial respirator should be removed outside the cathlab.

iii. Do not squeeze contaminated materials into the waste container in order to avoid aerosol generation.

iv. Dispose of all waste according to protocols and reprocess any reusable PPE.

v. Personnel to leave the room.

vi. All members should be monitored for fever and any respiratory symptoms for 14 days following the exposure with a COVID-19 patient (or follow local protocols).

\section{WHAT TO DO IN AEROSOL-GENERATING PROCEDURES}

In procedures that are aerosol generating (i.e. endotracheal intubation or transoesophageal echocardiography) or at high risk for requiring an aerosol-generating procedure (e.g. haemodynamic instability), recommendations are the same as for patients with confirmed COVID-19, regardless of the degree of suspicion of infection.

\section{WHAT TO DO IN PATIENTS WITHOUT SUSPECTED COVID-19 IN LOCAL AREAS WITH HIGH INFECTION BURDEN}

Follow the general rules of preventing infections in the cathlab, especially in patients transferred from the ED.

In procedures involving manipulation of the airway and/or oesophagus, or in those patients at risk of requiring this manipulation (e.g. unstable patients), recommendations are the same as those in patients with confirmed COVID-19.

i. In patients requiring intubation and mechanical ventilation or cardiopulmonary resuscitation, extreme care should be taken to apply preventive measures due to the high risk of droplet release.

ii. In those who may require transoesophageal echocardiography, manual ventilation, intubation, or any other type of airway manipulation, we recommend that the approach to infection prevention should be the same as that used in patients being tested for COVID-19 infection or with confirmed infection.

\section{KEY MESSAGES}

- It is recommended to dedicate at least one cathlab for the invasive treatment of suspected or confirmed COVID-19 patients

- It is crucial to establish clear pathways for COVID-19 patients in the cathlab at each intervention centre

- Only HCWs involved in the procedure should remain inside the cathlab; cathlab doors should be kept closed at all times.

- A surgical mask for the patients, and complete PPE for HCWs involved in the cathlab intervention

- All HCWs have to be routinely trained in the correct use of PPE (donning and doffing) 


\section{Conclusions}

There is no single solution for all invasive services and networks in the COVID-19 pandemic, and there will be a variation of the restrictions according to the stage of the crisis. At the onset, before the exponential rate of infections reduces bed and infrastructure capacity, there may still be the opportunity to treat the majority of ACS patients, whilst through the peak of infections in some hospitals there will simply be no capacity to treat more than the most acute and highest risk ACS patients. The strategies and measures outlined in this statement are intended to help with making these difficult decisions and organizing the service for maximum efficiency, whilst preserving the safety of the HCWs.

The vast experience gathered in the affected areas cannot be summarized in a single document, and we point to the power of social media and web-based reports that should be consulted regularly for new commentaries, developments, and exchange. The European Society of Cardiology has established a webpage summarizing advice on all aspects of cardiology relating to COVID-19: https://www.escardio.org/Education/COVID-19-and-Cardiology. Practical advice and case examples as well as interactive exchange of experience can be found on the PCR-online pages https://www. pcronline.com/Cases-resources-images/Zoom-on/COVID-19.

We are all moving together as an interventional community in this challenging time and, by helping each other with advice and exchange, we should hopefully make it through this crisis knowing we can provide the best possible care for our patients in the most difficult circumstances.

\section{Acknowledgements}

Alessandro Beneduce, MD, Rafael Romaguera, MD, and Francesca Ziviello, MD are thanked for their help in manuscript preparation.

\section{Conflict of interest statement}

The authors have no conflicts of interest to declare.

\section{References}

1. Li Q, Guan X, Wu P, Wang X, Zhou L, Tong Y, Ren R, Leung KSM, Lau EHY, Wong JY, Xing X, Xiang N, Wu Y, Li C, Chen Q, Li D, Liu T, Zhao J, Liu M, Tu W, Chen C, Jin L, Yang R, Wang Q, Zhou S, Wang R, Liu H, Luo Y, Liu Y, Shao G, Li H, Tao Z, Yang Y, Deng Z, Liu B, Ma Z, Zhang Y, Shi G, Lam TTY, Wu JT, Gao GF, Cowling BJ, Yang B, Leung GM, Feng Z. Early transmission dynamics in Wuhan, China, of novel coronavirus-infected pneumonia. N Engl J Med. 2020;382:1199-207.

2. Stefanini GG, Azzolini E, Condorelli G. Critical organizational issues for cardiologists in the COVID-19 outbreak: a frontline experience from Milan, Italy. Circulation. 2020; doi: 10.1161/CIRCULATIONAHA.120.047070.

3. Driggin E, Madhavan MV, Bikdeli B, Chuich T, Laracy J, Bondi-Zoccai G, Brown TS, Nigoghossian C, Zidar DA, Haythe J, Brodie D, Beckman JA, Kirtane AJ, Stone GW, Krumholz HM, Parikh SA. Cardiovascular considerations for patients, health care workers, and health systems during the coronavirus disease 2019 (COVID-19) pandemic. J Am Coll Cardiol. 2020; doi: 10.1016/j.jacc.2020.03.031.

4. Neumann FJ, Sousa-Uva M, Ahlsson A, Alfonso F, Banning AP, Benedetto U, Byrne RA, Collet JP, Falk V, Head SJ, Jüni P, Kastrati A, Koller A, Kristensen SD, Niebauer J, Richter DJ, Seferovic PM, Sibbing D, Stefanini GG, Windecker S, Yadav R, Zembala MO; ESC Scientific Document Group. 2018
ESC/EACTS Guidelines on myocardial revascularization. Eur Heart $J$. 2019;40:87-165.

5. Thygesen K, Alpert JS, Jaffe AS, Chaitman BR, Bax JJ, Morrow DA, White HD; ESC Scientific Document Group. Fourth universal definition of myocardial infarction (2018). Eur Heart J. 2019;40:237-69.

6. Chapman AR, Adamson PD, Shah ASV, Anand A, Strachan FE, Ferry AV, Ken Lee K, Berry C, Findlay I, Cruikshank A, Reid A, Gray A, Collinson PO, Apple F, McAllister DA, Maguire D, Fox KAA, Vallejos CA, Keerie C, Weir CJ, Newby DE, Mills NL. High-STEACS Investigators. High-sensitivity cardiac troponin and the universal definition of myocardial infarction. Circulation. 2020;141:161-71

7. Chapman AR, Shah ASV, Lee KK, Anand A, Francis O, Adamson P, McAllister DA, Strachan FE, Newby DE, Mills NL. Long-term outcomes in patients with type 2 myocardial infarction and myocardial injury. Circulation. 2018; 137:1236-45.

8. Wang D, Hu B, Hu C, Zhu F, Liu X, Zhang J, Wang B, Xiang H, Cheng Z, Xiong Y, Zhao Y, Li Y, Wang X, Peng Z. Clinical characteristics of 138 hospitalized patients with 2019 novel coronavirus-infected pneumonia in Wuhan, China. JAMA. 2020; doi: 10.1001/jama.2020.1585.

9. Huang C, Wang Y, Li X, Ren L, Zhao J, Hu Y, Zhang L, Fan G, Xu J, Gu X, Cheng Z, Yu T, Xia J, Wei Y, Wu W, Xie X, Yin W, Li H, Liu M, Xiao Y, Gao H, Guo L, Xie J, Wang G, Jiang R, Gao Z, Jin Q, Wang J, Cao B. Clinical features of patients infected with 2019 novel coronavirus in Wuhan, China. Lancet. 2020;395:497-506.

10. Shi S, Qin M, Shen B, Cai Y, Liu T, Yang F, Gong W, Liu X, Liang J, Zhao Q, Huang H, Yang B, Huang C. Association of cardiac injury with mortality in hospitalized patients with COVID-19 in Wuhan, China. JAMA Cardiol. 2020; doi:10.1001/jamacardio.2020.0950.

11. Zhou F, Yu T, Du R, Fan G, Liu Y, Liu Z, Xiang J, Wang Y, Song B, Gu X, Guan L, Wei Y, Li H, Wu X, Xu J, Tu S, Zhang Y, Chen H, Cao B. Clinical course and risk factors for mortality of adult inpatients with COVID-19 in Wuhan, China: a retrospective cohort study. Lancet. 2020;95:1054-62.

12. Clerkin KJ, Fried JA, Raikhelkar J, Sayer G, Griffin JM, Masoumi A, Jain SS, Burkhoff D, Kumaraiah D, Rabbani L, Schwartz A, Uriel N. Coronavirus disease 2019 (COVID-19) and cardiovascular sisease. Circulation. 2020; doi: 10.1161/CIRCULATIONAHA.120.046941.

13. Tavazzi G, Pellegrini C, Maurelli M, Belliato M, Sciutti F, Bottazzi A, Sepe PA, Resasco T, Camporotondo R, Bruno R, Baldanti F, Paolucci S, Pelenghi S, Iotti GA, Mojoli F, Arbustini E. Myocardial localization of coronavirus in COVID-19 cardiogenic shock. Eur J Heart Fail. 2020; doi: 10.1002/ejhf.1828.

14. McCarthy CP, Raber I, Chapman AR, Sandoval Y, Apple FS, Mills NL, Januzzi JL Jr. Myocardial injury in the era of high-sensitivity cardiac troponin assays: a practical approach for clinicians. JAMA Cardiol. 2019;4:1034-42.

15. Zeng J, Huang J, Pan L. How to balance acute myocardial infarction and COVID-19: the protocols from Sichuan Provincial People's Hospital. Intensive Care Med. 2020; doi: 10.1007/s00134-020-05993-9.

16. Skulstad H, Cosyns B, Popescu BA, Galderisi M, Salvo GD, Donal E, Petersen S, Gimelli A, Haugaa KH, Muraru D, Almeida AG, Schulz-Menger J, Dweck MR, Pontone G, Sade LE, Gerber B, Maurovich-Horvat P, Bharucha T, Cameli M, Magne J, Westwood M, Maurer G, Edvardsen T. COVID-19 pandemic and cardiac imaging: EACVI recommendations on precautions, indications, prioritization, and protection for patients and healthcare personnel. Eur Heart J Cardiovasc Imaging. 2020; doi: 10.1093/ehjci/jeaa072.

17. World Health Organization. Coronavirus disease (COVID-19) outbreak: rights, roles and responsibilities of health workers, including key considerations for occupational safety and health: interim guidance, 19 March 2020. (https://www.who.int/docs/default-source/coronaviruse/who-rights-rolesrespon-hw-covid-19. pdf?sfvrsn=bcabd401_0).

18. World Health Organization. Infection prevention and control during health care when COVID-19 is suspected. Interim Guidance Geneva 2020 WHO/2019-nCoV/ 
IPC/v20201. (https://www.who.int/publications-detail/infection-prevention-andcontrol-during-health-care-when-novel-coronavirus-(ncov)-infection-is-susp ected).

19. World Health Organization. Rational use of personal protective equipment for coronavirus disease 2019 (COVID-19). Interim guidance 27 February 2020 (https://apps.who.int/iris/bitstream/handle/10665/331215/WHO-2019-nCovIPCPPE_use-2020.1-eng.pdf).

20. Tam CF, Cheung KS, Lam S, Wong A, Yung A, Sze M, Lam YM, Chan C, Tsang TC, Tsui M, Tse HF, Siu CW. Impact of coronavirus disease 2019 (COVID-19) outbreak on ST-segment-elevation myocardial infarction care in Hong Kong, China. Circ Cardiovasc Qual Outcomes. 2020;13:e006631.

21. Pilz S, Theiler-Schwetz V, Trummer C. Letter by Pilz et al Regarding article, 'Impact of Coronavirus Disease 2019 (COVID-19) Outbreak on ST-Elevation Myocardial Infarction Care in Hong Kong, China'. Circ Cardiovasc Qual Outcomes 2020; doi: 10.1161/CIRCOUTCOMES.120.006734.

22. Ibanez B, James S, Agewall S, Antunes MJ, Bucciarelli-Ducci C, Bueno H, Caforio ALP, Crea F, Goudevenos JA, Halvorsen S, Hindricks G, Kastrati A, Lenzen MJ, Prescott E, Roffi M, Valgimigli M, Varenhorst C, Vranckx P, Widimsky P; ESC Scientific Document Group. 2017 ESC Guidelines for the management of acute myocardial infarction in patients presenting with ST-segment elevation: The Task Force for the management of acute myocardial infarction in patients presenting with ST-segment elevation of the European Society of Cardiology (ESC). Eur Heart J. 2018;39:119-77.

23. Roffi M, Patrono C, Collet JP, Mueller C, Valgimigli M, Andreotti F, Bax JJ, Borger MA, Brotons C, Chew DP, Gencer B, Hasenfuss G, Kjeldsen K, Lancellotti P, Landmesser U, Mehilli J, Mukherjee D, Storey RF, Windecker S; ESC Scientific Document Group. 2015 ESC Guidelines for the management of acute coronary syndromes in patients presenting without persistent ST-segment elevation: Task Force for the Management of Acute Coronary Syndromes in Patients Presenting without Persistent ST-Segment Elevation of the European Society of Cardiology (ESC). Eur Heart J. 2016;37:267-315.

24. van Diepen S, Katz JN, Albert NM, Henry TD, Jacobs AK, Kapur NK, Kilic A, Menon V, Ohman EM, Sweitzer NK, Thiele H, Washam JB, Cohen MG; American Heart Association Council on Clinical Cardiology; Council on Cardiovascular and Stroke Nursing; Council on Quality of Care and Outcomes Research; and Mission: Lifeline. Contemporary management of cardiogenic shock: a Scientific Statement from the American Heart Association. Circulation. 2017;136:e232-e68.

25. Baran DA, Grines CL, Bailey S, Burkhoff D, Hall SA, Henry TD, Hollenberg SM, Kapur NK, O’Neill W, Ornato JP, Stelling K, Thiele H, van Diepen S, Naidu SS. SCAI clinical expert consensus statement on the classification of cardiogenic shock: This document was endorsed by the American College of Cardiology (ACC), the American Heart Association (AHA), the Society of Critical Care Medicine (SCCM), and the Society of Thoracic Surgeons (STS) in April 2019. Catheter Cardiovasc Interv. 2019;94:29-37.

26. Johnson DB, Balko JM, Compton ML, Chalkias S, Gorham J, Xu Y, Hicks M, Puzanov I, Alexander MR, Bloomer TL, Becker JR, Slosky DA, Phillips EJ, Pilkinton MA, Craig-Owens L, Kola N, Plautz G, Reshef DS, Deutsch JS, Deering RP, Olenchock BA, Lichtman AH, Roden DM, Seidman CE, Koralnik IJ, Seidman JG, Hoffman RD, Taube JM, Diaz LA Jr, Anders RA, Sosman JA, Moslehi JJ. Fulminant myocarditis with combination immune checkpoint blockade. $N$ Engl J Med. 2016;375:1749-55.

27. Sandoval Y, Jaffe AS. Type 2 myocardial infarction: JACC Review Topic of the Week. J Am Coll Cardiol. 2019;73:1846-60.

28. Steeds RP, Garbi M, Cardim N, Kasprzak JD, Sade E, Nihoyannopoulos P, Popescu BA, Stefanidis A, Cosyns B, Monaghan M, Aakhus S, Edvardsen T, Flachskampf F, Galiuto L, Athanassopoulos G, Lancellotti P; 2014-2016 EACVI Scientific Documents Committee; 2014-2016 EACVI Scientific Documents Committee. EACVI appropriateness criteria for the use of transthoracic echocardiography in adults: a report of literature and current practice review. Eur Heart J Cardiovasc Imaging. 2017;18:1191-204.
29. Neskovic AN, Skinner H, Price S, Via G, De Hert S, Stankovic I, Donal E, Muraru D, Sloth E, Gargani L, Cardim N, Stefanidis A, Cameli M, Habib G, Cosyns B, Lancellotti P, Edvardsen T, Popescu BA; Reviewers: This document was reviewed by members of the 2016-2018 EACVI Scientific Documents Committee. Focus cardiac ultrasound core curriculum and core syllabus of the European Association of Cardiovascular Imaging. Eur Heart J Cardiovasc Imaging. 2018;19:475-81.

30. Lorusso R, Centofanti P, Gelsomino S, Barili F, Di Mauro M, Orlando P, Botta L, Milazzo F, Actis Dato G, Casabona R, Casali G, Musumeci F, De Bonis M, Zangrillo A, Alfieri O, Pellegrini C, Mazzola S, Coletti G, Vizzardi E, Bianco R, Gerosa G, Massetti M, Caldaroni F, Pilato E, Pacini D, Di Bartolomeo R, Marinelli G, Sponga S, Livi U, Mauro R, Mariscalco G, Beghi C, Miceli A, Glauber M, Pappalardo F, Russo CF; GIROC Investigators. Venoarterial extracorporeal membrane oxygenation for acute fulminant myocarditis in adult patients: a 5- year multi-institutional experience. Ann Thorac Surg. 2016;101:919-26.

31. Australia and New Zealand Extracorporeal Membrane Oxygenation (ANZ ECMO) Influenza Investigators, Davies A, Jones D, Bailey M, Beca J, Bellomo R, Blackwell N, Forrest P, Gattas D, Granger E, Herkes R, Jackson A, McGuinness S, Nair P, Pellegrino V, Pettilä V, Plunkett B, Pye R, Torzillo P, Webb S, Wilson M, Ziegenfuss M. Extracorporeal membrane oxygenation for 2009 influenza A(H1N1) acute respiratory distress syndrome. JAMA. 2009;302: 1888-95.

32. World Health Organization. Clinical management of severe acute respiratory infection (SARI) when COVID-19 disease is suspected. Interim guidance 13 March 2020 World Health Organization. 2020.

33. Abrams D, Garan AR, Abdelbary A, Bacchetta M, Bartlett RH, Beck J, Belohlavek J, Chen YS, Fan E, Ferguson ND, Fowles JA, Fraser J, Gong M, Hassan IF, Hodgson C, Hou X, Hryniewicz K, Ichiba S, Jakobleff WA, Lorusso R, MacLaren G, McGuinness S, Mueller T, Park PK, Peek G, Pellegrino V, Price S, Rosenzweig EB, Sakamoto T, Salazar L, Schmidt M, Slutsky AS, Spaulding C, Takayama H, Takeda K, Vuylsteke A, Combes A, Brodie D; International ECMO Network (ECMONet) and The Extracorporeal Life Support Organization (ELSO). Position paper for the organization of ECMO programs for cardiac failure in adults. Intensive Care Med. 2018;44:717-29.

34. Grasselli G, Zangrillo A, Zanella A, Antonelli M, Cabrini L, Castelli A, Cereda D, Coluccello A, Foti G, Fumagalli R, Iotti G, Latronico N, Lorini L, Merler S, Natalini G, Piatti A, Ranieri MV, Scandroglio AM, Storti E, Cecconi M, Pesenti A; COVID-19 Lombardy ICU Network. Baseline characteristics and outcomes of 1591 patients infected with SARS-CoV-2 admitted to ICUs of the Lombardy region, Italy. JAMA. 2020; doi: 10.1001/jama.2020.5394.

35. Repesse X, Charron C, Vieillard-Baron A. Acute cor pulmonale in ARDS: rationale for protecting the right ventricle. Chest. 2015;147:259-65.

36. Abrams D, Ferguson ND, Brochard L, Fan E, Mercat A, Combes A, Pellegrino V, Schmidt M, Slutsky AS, Brodie D. ECMO for ARDS: from salvage to standard of care? Lancet Respir Med. 2019;7:108-10.

37. Reis Miranda D, van Thiel R, Brodie D, Bakker J. Right ventricular unloading after initiation of venovenous extracorporeal membrane oxygenation. Am J Respir Crit Care Med. 2015;191:346-8.

38. Ramanathan K, Antognini D, Combes A, Paden M, Zakhary B, Ogino M, MacLaren G, Brodie D, Shekar K. Planning and provision of ECMO services for severe ARDS during the COVID-19 pandemic and other outbreaks of emerging infectious diseases. Lancet Respir Med. 2020; doi: 10.1016/S22132600(20) 30121-1.

39. Kociol RD, Cooper LT, Fang JC, Moslehi JJ, Pang PS, Sabe MA, Shah RV, Sims DB, Thiene G, Vardeny O; American Heart Association Heart Failure and Transplantation Committee of the Council on Clinical Cardiology. Recognition and initial management of fulminant myocarditis: a Scientific Statement from the American Heart Association. Circulation. 2020;141:e69-e92.

40. Day M. Covid-19: identifying and isolating asymptomatic people helped eliminate virus in Italian village. $B M J .2020 ; 368: \mathrm{m} 1165$. 
41. Bai Y, Yao L, Wei T, Tian F, Jin DY, Chen L, Wang M. Presumed asymptomatic carrier transmission of COVID-19. JAMA. 2020; doi: 10.1001/jama. 2020.2565 .

42. Schwartz J, King CC, Yen MY. Protecting health care workers during the COVID-19 coronavirus outbreak - lessons from Taiwan's SARS response. Clin Infect Dis. 2020; doi: 10.1093/cid/ciaa255.

43. Wang J, Zhou M, Liu F. Exploring the reasons for healthcare workers infected with novel coronavirus disease 2019 (COVID-19) in China. $J$ Hosp Infect. 2020; doi: 10.1016/j.jhin.2020.03.002.

44. Wong J, Goh QY, Tan Z, Lie SA, Tay YC, Ng SY, Soh CR. Preparing for a COVID-19 pandemic: a review of operating room outbreak response measures in a large tertiary hospital in Singapore. Can J Anaesth. 2020; doi: 10.1007/s12630-020-01620-9.

45. Huh S. How to train the health personnel for protecting themselves from novel coronavirus (COVID-19) infection during their patient or suspected case care. J Educ Eval Health Prof. 2020;17:10.

46. Welt FGP, Shah PB, Aronow HD, Bortnick AE, Henry TD, Sherwood MW, Young MN, Davidson LJ, Kadavath S, Mahmud E, Kirtane AJ; American College of Cardiology's (ACC) Interventional Council and the Society of Cardiovascular Angiography and Intervention (SCAI). Catheterization laboratory considerations during the coronavirus (COVID-19) pandemic: from ACC's Interventional Council and SCAI. J Am Coll Cardiol. 2020; doi: 10.1016/j.jacc.2020.03.021.

47. Romaguera R, Cruz-Gonzalez I, Ojeda S, Jiménez-Candil J, Calvo D, García Seara J, Canadas-Godoy V, Calvo E, Brugaletta S, Sánchez Ledesma M, Moreno R. Consensus document of the Interventional Cardiology and Heart Rhythm Associations of the Spanish Society of Cardiology on the management of invasive cardiac procedure rooms during the COVID-19 coronavirus outbreak. REC Interv Cardiol. 2020; doi.org/10.24875/RECICE.M20000116.

48. Tarantini G, Fraccaro C, Chieffo A, Marchese A, Tarantino FF, Rigattieri S, Limbruno U, Mauro C, La Manna A, Castiglioni B, Longoni M, Berti S, Greco F, Musumeci G, Esposito G; GISE. Italian Society of Interventional Cardiology (GISE) Position Paper for cath lab-specific preparedness recommendations for healthcare providers in case of suspected, probable or confirmed cases of COVID-19. Catheter Cardiovasc Interv. 2020; doi: $10.1002 / \mathrm{ccd} .28888$.

\section{Supplementary material}

The supplementary data are published online at:

https://eurointervention.pcronline.com/

doi/10.4244/EIJY20M05 01 
Supplemental Table1. Recommendations for fibrinolytic therapy Extracted from ESC STEMI guidelines (Ibanez B et al , Eur Heart J. 2018; 39(2):119-177)

\begin{tabular}{|c|c|c|}
\hline Recommendations & Class & Level \\
\hline $\begin{array}{l}\text { When fibrinolysis is the reperfusion strategy, it is recommended to initiate this treatment as soon as possible } \\
\text { after STEMI diagnosis, preferably in the pre-hospital setting }\end{array}$ & 1 & A \\
\hline A fibrin-specific agent (i.e. tenecteplase, alteplase, or reteplase) is recommended & 1 & B \\
\hline A half-dose of tenecteplase should be considered in patients $\geq 75$ years of age & Ila & B \\
\hline \multicolumn{3}{|l|}{ Antiplatelet co-therapy with fibrinolysis } \\
\hline Oral or i.v. aspirin is indicated & 1 & B \\
\hline Clopidogrel is indicated in addition to aspirin & 1 & A \\
\hline $\begin{array}{l}\text { DAPT (in the form of aspirin plus a P2Y12 inhibitor) is indicated for up to } 1 \text { year in patients undergoing } \\
\text { fibrinolysis and subsequent } \mathrm{PCl} \text {. }\end{array}$ & 1 & $\mathrm{C}$ \\
\hline \multicolumn{3}{|l|}{ Anticoagulation co-therapy with fibrinolysis } \\
\hline $\begin{array}{l}\text { Anticoagulation is recommended in patients treated with lytics until revascularization (if performed) or for the } \\
\text { duration of hospital stay up to } 8 \text { days. The anticoagulant can be: }\end{array}$ & 1 & A \\
\hline - Enoxaparin i.v. followed by s.c. (preferred over UFH) & 1 & A \\
\hline - UFH given as a weight-adjusted i.v. bolus followed by infusion. & 1 & B \\
\hline - In patients treated with streptokinase: fondaparinux i.v. bolus followed by an s.c. dose 24 h later. & IIa & $\mathrm{B}$ \\
\hline
\end{tabular}

DAPT=dual antiplatelet therapy; PCI=percutaneous coronary interventions; UFH=unfractionated heparin; STEMI=ST-elevation myocardial infarction. 
Supplemental Table 2. Doses of fibrinolytic agents and antithrombotic co-therapies: Extracted ESC STEMI guidelines (Ibanez B et al, Eur Heart J. 2018; 39(2):119-177)

\begin{tabular}{|c|c|c|}
\hline Drug & Initial treatment & Specific contra-indications \\
\hline \multicolumn{3}{|c|}{ Doses of fibrinolytic therapy } \\
\hline Streptokinase & 1.5 million units over $30-60$ min i.v. & $\begin{array}{l}\text { Previous treatment with } \\
\text { streptokinase or anistreplase }\end{array}$ \\
\hline Alteplase (tPA) & $\begin{array}{l}15 \mathrm{mg} \text { i.v. bolus } \\
0.75 \mathrm{mg} / \mathrm{kg} \text { i.v. over } 30 \mathrm{~min} \text { (up to } 50 \mathrm{mg} \text { ) } \\
\text { then } 0.5 \mathrm{mg} / \mathrm{kg} \text { i.v. over } 60 \mathrm{~min} \text { (up to } 35 \mathrm{mg} \text { ) }\end{array}$ & \\
\hline Reteplase (rPA) & 10 units +10 units i.v. bolus given 30 min apart & \\
\hline $\begin{array}{l}\text { Tenecteplase (TNK- } \\
\text { tPA) }\end{array}$ & $\begin{array}{l}\text { Single i.v. bolus: } \\
30 \mathrm{mg}(6000 \mathrm{IU}) \text { if }<60 \mathrm{~kg} \\
35 \mathrm{mg}(7000 \mathrm{IU}) \text { if } 60 \text { to }<70 \mathrm{~kg} \\
40 \mathrm{mg}(8000 \mathrm{IU}) \text { if } 70 \text { to }<80 \mathrm{~kg} \\
45 \mathrm{mg}(9000 \mathrm{IU}) \text { if } 80 \text { to }<90 \mathrm{~kg} \\
50 \mathrm{mg}(10000 \mathrm{IU}) \text { if } \geq 90 \mathrm{~kg} \\
\text { It is recommended to reduce to half-dose in patients } \geq 75 \text { years of age. }{ }^{|2|}\end{array}$ & \\
\hline \multicolumn{3}{|c|}{ Doses of antiplatelet co-therapies } \\
\hline Aspirin & $\begin{array}{l}\text { Starting dose of } 150-300 \mathrm{mg} \text { orally (or } 75-250 \mathrm{mg} \text { intravenously if oral ingestion is not possible), } \\
\text { followed by a maintenance dose of } 75-100 \mathrm{mg} / \text { day }\end{array}$ & \\
\hline Clopidogrel & $\begin{array}{l}\text { Loading dose of } 300 \mathrm{mg} \text { orally, followed by a maintenance dose of } 75 \mathrm{mg} / \mathrm{day} \text {. } \\
\text { In patients } \geq 75 \text { years of age: loading dose of } 75 \mathrm{mg} \text {, followed by a maintenance dose of } 75 \mathrm{mg} / \text { day. }\end{array}$ & \\
\hline \multicolumn{3}{|c|}{ Doses of anticoagulant co-therapies } \\
\hline Enoxaparin & $\begin{array}{l}\text { In patients }<75 \text { years of age: } \\
30 \text { mg i.v. bolus followed I5 min later by I mg/kg s.c. every } 12 \text { hours until revascularization or } \\
\text { hospital discharge for a maximum of } 8 \text { days. The first two s.c. doses should not exceed } 100 \mathrm{mg} \\
\text { per injection. } \\
\text { In patients } \geq 75 \text { years of age: } \\
\text { no i.v. bolus; start with first s.c. dose of } 0.75 \mathrm{mg} / \mathrm{kg} \text { with a maximum of } 75 \mathrm{mg} \text { per injection for } \\
\text { the first two s.c. doses. } \\
\text { In patients with eGFR }<30 \mathrm{~mL} / \mathrm{min} / \mathrm{l} .73 \mathrm{~m}^{2} \text {, regardless of age, the s.c. doses are given once every } \\
24 \text { hours. }\end{array}$ & \\
\hline UFH & $\begin{array}{l}60 \mathrm{IU} / \mathrm{kg} \text { i.v. bolus with a maximum of } 4000 \mathrm{IU} \text { followed by an i.v. infusion of I2 IU/kg with a } \\
\text { maximum of } 1000 \mathrm{IU} / \text { hour for } 24-48 \text { hours. Target aPTT: } 50-70 \text { s or I.5 to } 2.0 \text { times that of } \\
\text { control to be monitored at } 3,6,12 \text { and } 24 \text { hours. }\end{array}$ & \\
\hline $\begin{array}{l}\text { Fondaparinux (only } \\
\text { with streptokinase) }\end{array}$ & $2.5 \mathrm{mg}$ i.v. bolus followed by a s.c. dose of $2.5 \mathrm{mg}$ once daily up to 8 days or hospital discharge. & \\
\hline
\end{tabular}


Supplemental Table 3 Impact of COVID-19 Pandemic on STEMI Networks in Europe 15 March 2020

\begin{tabular}{|c|c|c|c|c|}
\hline Country & $\begin{array}{l}\text { Changes } \\
\text { in STEMI } \\
\text { network }\end{array}$ & $\begin{array}{l}\text { Personnel/logistic } \\
\text { changes }\end{array}$ & $\begin{array}{l}\text { Consideration to } \\
\text { Fibrinolysis }\end{array}$ & SARS-CoV-2 testing strategy \\
\hline $\begin{array}{l}\text { Austria } \\
\text { (Vienna network) }\end{array}$ & None & $\begin{array}{l}\text { Shared human and } \\
\text { logistic resources in } \\
\text { case one hub is } \\
\text { quarantined; dedicated } \\
\text { cathlab. }\end{array}$ & $\begin{array}{l}\text { Only if pPCI } \\
\text { cannot be timely } \\
\text { according to ESC } \\
\text { guidelines }\end{array}$ & $\begin{array}{l}\text { Only for patients with clinically } \\
\text { suspected infection }\end{array}$ \\
\hline France & $\begin{array}{l}\text { COVID-19 } \\
\text { dedicated } \\
\text { hubs and } \\
\text { wards }\end{array}$ & Dedicated cathlab & Never & $\begin{array}{l}\text { Only for patients with clinically } \\
\text { suspected infection }\end{array}$ \\
\hline Germany & $\begin{array}{l}\text { COVID- } \\
\text { 19dedicated } \\
\text { hubs or wards }\end{array}$ & $\begin{array}{l}\text { Dedicated cathlab, } \\
\text { shorter CCU stay for } \\
\text { non-COVID-19 patients }\end{array}$ & $\begin{array}{l}\text { Only if pPCI } \\
\text { cannot be timely } \\
\text { according to ESC } \\
\text { guidelines }\end{array}$ & $\begin{array}{l}\text { Only for patients with clinically } \\
\text { suspected infection }\end{array}$ \\
\hline Italy & $\begin{array}{l}\text { COVID } \\
\text { 19dedicated } \\
\text { hubs or wards }\end{array}$ & $\begin{array}{l}\text { Shared human and } \\
\text { logistic resources in } \\
\text { case one hub is }\end{array}$ & $\begin{array}{l}\text { Only if pPCI } \\
\text { cannot be timely }\end{array}$ & $\begin{array}{l}\text { Only for patients with clinically } \\
\text { suspected infection; but in the } \\
\text { highest impacted regions all STEMI }\end{array}$ \\
\hline
\end{tabular}




\begin{tabular}{|c|c|c|c|c|}
\hline & & $\begin{array}{l}\text { quarantined; dedicated } \\
\text { cathlab. }\end{array}$ & $\begin{array}{l}\text { according to ESC } \\
\text { guidelines }\end{array}$ & $\begin{array}{l}\text { are tested irrespectively from } \\
\text { symptoms }\end{array}$ \\
\hline Norway & None & $\begin{array}{l}\text { Dedicated cathlabs in } \\
\text { the hubs (pPCI is } \\
\text { already very } \\
\text { centralized) }\end{array}$ & $\begin{array}{l}\text { Only if pPCI } \\
\text { cannot be } \\
\text { performed } \\
\text { according to ESC } \\
\text { guidelines }\end{array}$ & $\begin{array}{l}\text { Only for patients with clinically } \\
\text { suspected infection }\end{array}$ \\
\hline Poland & $\begin{array}{l}\text { Covid-19 } \\
\text { dedicated } \\
\text { hubs and } \\
\text { wards }\end{array}$ & $\begin{array}{l}\text { Dedicated cathlab for } \\
\text { Covid-19 positive or } \\
\text { high } \\
\text { patients }\end{array}$ & $\begin{array}{l}\text { Only if pPCI } \\
\text { cannot be timely, } \\
\text { according to ESC } \\
\text { Guidelines }\end{array}$ & $\begin{array}{l}\text { Only for patients with clinically } \\
\text { suspected infection }\end{array}$ \\
\hline Spain & $\begin{array}{l}\text { None. } \\
\text { Dedicated } \\
\text { wards only in } \\
\text { a small region } \\
\text { (Pais Vasco). }\end{array}$ & $\begin{array}{l}\text { Shorter CCU stay. } \\
\text { division of teams to } \\
\text { avoid multiple } \\
\text { contagion. }\end{array}$ & $\begin{array}{l}\text { Only in } 1 \\
\text { community } \\
\text { hospital if SARS } \\
\text { COV is suspected }\end{array}$ & $\begin{array}{l}\text { Only for patients with clinically } \\
\text { suspected infection }\end{array}$ \\
\hline Sweden & None & $\begin{array}{l}\text { Shared logistic } \\
\text { resources between } \\
\text { hubs in case of } \\
\text { shortage of personnel. } \\
\text { Dedicated cathlab. }\end{array}$ & $\begin{array}{l}\text { Only if pPCI } \\
\text { cannot be timely } \\
\text { according to ESC } \\
\text { guidelines }\end{array}$ & $\begin{array}{l}\text { Only for patients with clinically } \\
\text { suspected infection }\end{array}$ \\
\hline
\end{tabular}




\begin{tabular}{|c|c|c|c|c|}
\hline Switzerland & $\begin{array}{l}\text { None. More } \\
\text { rapid transfer } \\
\text { to spoke } \\
\text { hospitals after } \\
\text { primary PCI } \\
\text { (to unload } \\
\text { hubs, usually } \\
\text { COVID-19) }\end{array}$ & $\begin{array}{l}\text { Shared logistic } \\
\text { resources in case one } \\
\text { shortage of personnel } \\
\text { occurs in of the hubs }\end{array}$ & Never & $\begin{array}{l}\text { Only for patients with clinically } \\
\text { suspected infection }\end{array}$ \\
\hline United Kingdom & None & $\begin{array}{l}\text { Shared human and } \\
\text { logistic resources in } \\
\text { case one hub has } \\
\text { shortage of personnel; } \\
\text { dedicated cathlab. }\end{array}$ & $\begin{array}{l}\text { Only if pPCI } \\
\text { cannot be timely } \\
\text { according to ESC } \\
\text { guidelines }\end{array}$ & $\begin{array}{l}\text { Only for patients with clinically } \\
\text { suspected infection }\end{array}$ \\
\hline
\end{tabular}

pPCI= primary percutaneous coronary intervention ; CCU= coronary care unit; STEMI= ST elevation myocardial infarctio 
Supplemental Table 4. Daily checklist of PPE and checklist of crash in cathlab

\begin{tabular}{|c|}
\hline Daily checklist of PPE in cath lab \\
\hline Surgical mask \\
\hline Respirator N95 or FFP2 standard and FFP3, or equivalent \\
\hline Long-sleeved water-resistant gown \\
\hline Sterile standard gown \\
\hline Gloves \\
\hline Hair covers \\
\hline Eye protection (goggles or face shield, better if disposable) \\
\hline Apron (for aerosol-generating procedures such as intubation) \\
\hline Shoe covers \\
\hline Daily checklist of crash cart in cath lab \\
\hline $\begin{array}{l}\text { Heat and moisture exchanger (HME) filters to be placed on any } \\
\text { interface (mask, circuit, endotracheal tube, supraglottic devices, } \\
\text { introducer/exchange pipes) }\end{array}$ \\
\hline Laryngoscope \\
\hline Masks \\
\hline Circuits \\
\hline Endotracheal tubes \\
\hline Supraglottic devices \\
\hline Introducer/exchange pipes \\
\hline Aspirator: closed system \\
\hline Anti-fogging system \\
\hline Any potential useful drugs already prepared and double checked \\
\hline Clamp, if necessary to disconnect the patient from the ventilator \\
\hline
\end{tabular}

